Brit. J. vener. Dis. (1961), 37, 190.

\title{
X-RAY PHOTOGRAPHY OF UNERUPTED PERMANENT TEETH IN CONGENITAL SYPHILIS*†
}

\author{
BY \\ TAUNO PUTKONEN AND YRJÖ V. PAATERO \\ From the Department of Dermatology and Venereology, \\ University Hospital, Helsinki, Finland
}

Changes in the permanent upper central incisors (Hutchinsonian teeth) and in the permanent first molars (Moon, 1877, 1884; Pflüger, 1924) are two of the most important stigmata of late congenital syphilis. These stigmata are not seen until the second dentition, in the incisors after about 7 years of age and in the molars after the 6th year. In radiographs however, Stokes and Gardner (1923) demonstrated in a child aged 5 years the changes, described by Hutchinson, in unerupted permanent upper central incisors and Pincherle (1937) noted changes in the permanent first molars. Further reports of such observations have also been published (Quinlan, 1927; Pitts, 1927; Meyer-Buley, 1930; etc.), but a search of the literature revealed only one case (Sarnat, Schour, and Heupel, 1941) in which the $x$-ray findings had been checked after the second dentition; in this case the syphilitic changes were associated with enamel hypoplasia.

The interpretation of $x$-ray findings in the case of unerupted teeth is frequently difficult, and for this reason our experience based on $x$-ray examination of the unerupted teeth of patients with congenital syphilis and on follow-up examinations after eruption of the teeth, may be of interest.

\section{Report of a Syphilitic Family}

A 35-year-old dairymaid and her three children were sent, in June, 1951, to the State Hospital for Venereal Diseases, Kumpulaf because positive serological tests for syphilis (STS) had been found in her and the two younger children, aged respectively 4 years and 5 months and 3 years. In the eldest child, who was 6 years and 8 months old, the STS were negative.

The mother was not aware of her disease until the blood test was taken, but she remembered that before the birth

\footnotetext{
* Supported by a grant from Sigrid Jusélius Stiftelse.

+ Received for publication November 15, 1960.

$¥$ Now incorporated in the Department of Dermatology and Venereology, University Hospital, Helsinki.
}

of her second child she had had a sore throat and hoarseness for several weeks and excessive falling out of hair. Apart from the positive STS, the only additional evidence of syphilis was an increase in the cell count and protein, and a positive Wassermann reaction in the cerebrospinal fluid. She was therefore suffering from asymptomatic neurosyphilis. The father of the children refused to come for examination.

The history of the eldest child revealed no features of special importance, but the second child had had red patches on the face, hands, and feet in early infancy and medical advice had been sought because of coughs and snuffles. While a baby, she was also much weaker than her elder brother but she walked at 1 year and 2 months. The youngest child had rickets, and at 3 years of age Harrison's groove still persisted.

Clinical signs of congenital syphilis were not found in any of the three children. $X$-rays of the long bones, lumbar puncture, and ophthalmological examination were also negative. The STS were positive in the two younger children but negative in the eldest. The results of blood tests 9 years after penicillin treatment are shown in the Table.

TABLE

RESULTS OF SEROLOGICAL TESTS FOR SYPHILIS

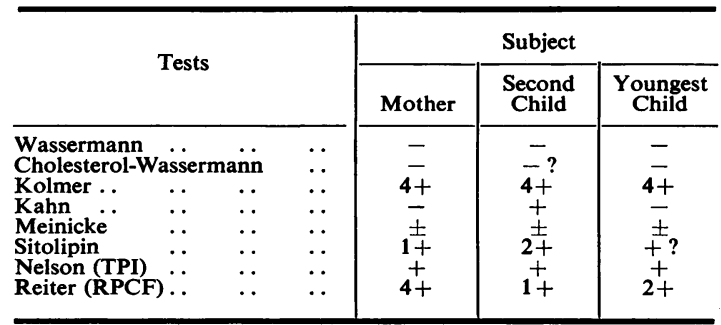

Thus, in this family it appears that the eldest child was healthy and that the mother had contracted syphilis one year before the birth of the second child. This child had a skin eruption and rhinitis in infancy, and positive STS. The youngest child also had syphilis but did not show the early signs. She had rickets in infancy. 
Teeth.-In the oldest, healthy, child the erupted permanent upper central incisors and all first molars were normal. The first dental examination of the younger, syphilitic children showed that only the deciduous teeth had erupted. In the older of the two younger children, the unerupted, permanent, central incisors appeared on $x$ ray to be classical Hutchinsonian teeth (Fig. 1A), barrel-shaped and with a distinct notch in the cutting edge. The youngest child (Fig. 1 B), however, had central incisors with fairly parallel lateral margins and there was no notching. In neither child did $x$ rays of the unerupted first molars show any features indicating congenital syphilis.

Follow-up examination of the teeth, 9 years later, showed that in the second child the only remaining permanent first molar was normal and the upper central incisors were typically Hutchinsonian (Fig. 1A); caries had necessitated filling of the right central incisor one year before. The $x$ rays had thus given a true picture of these teeth. It was also found that the left lower central incisor narrowed typically towards the cutting edge and showed a slight notch.

In the youngest child, follow-up examination of the teeth clearly revealed that she had suffered from rickets (Fig. 1B). There was wide enamel hypoplasia of the distal part of the right upper central incisor, and a typical swelling of enamel with three mamillons was seen at the upper border of the area of hypoplasia. The medial margin of this tooth was concave to some extent. These changes could be detected in the earlier $x$ rays on closer reexamination. There was slight enamel hypoplasia of the left central incisor and also at the points of all the canines. The lower first molars also showed distinct enamel hypoplasia, although this had not been visible in the $x$ rays (Fig. 1C).
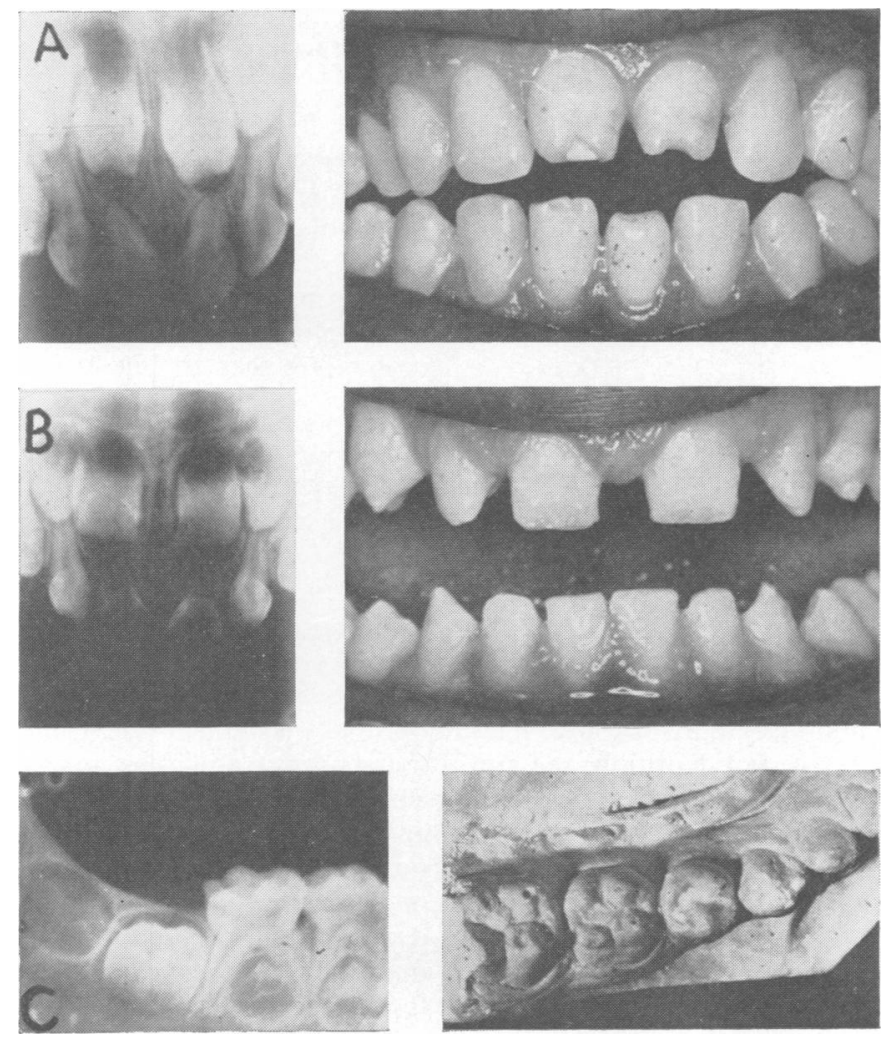

FIG. 1. $-X$ rays of unerupted teeth of the syphilitic children dealt with in the family report, and photographs of the same teeth after their
eruption. A, second child; B and C, youngest child, who also had rickets. 


\section{Series Examined}

The whole series consisted of 42 children with congenital syphilis treated at Kumpula Hospital in the period 1949-1953. Their ages ranged from 13 months to 6 years and 11 months (average, 4 yrs $9 \mathrm{mths}$ ). The diagnosis was based in all cases on positive STS and, with one exception, the mothers also had verified syphilis. (In this one case, the mother could not be traced, but interstitial keratitis and Clutton's joints proved the disease to be congenital.) Other findings deserving mention are: congenital syphilis in a sibling (eighteen cases), keratitis (ten cases), sabre-shaped tibia (two cases), and scars from rhagades (three cases). There was also a history of skin eruption and rhinitis in infancy in eight patients.

An intra-oral $x$ ray of the unerupted permanent upper centrals was taken in all 42 cases; in ten patients, $x$ rays of the upper and lower first molars were also taken. Even in the youngest patient (Fig. 2), the distal third of the crown-diagnostically the most important part-was already visible in the $x$-ray. All patients under one year old were excluded, because at most only the cutting edge of the upper centrals was calcified, and no idea of the lateral margins could be obtained in these infants.

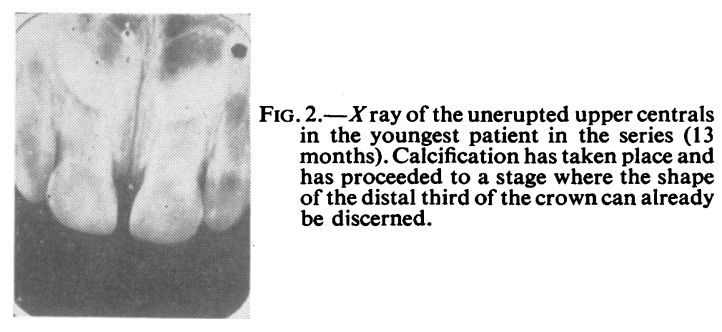

To check the $x$-ray findings, follow-up examinations were made after the second dentition, the aim being to examine especially those children in whom the $x$ rays had shown some abnormality. Only twelve children could be traced: some families had moved, some children lived too far away, and some parents were trying by every conceivable means to conceal from their children the disease, which had already been adequately treated.

At follow-up examination the age of the patients varied from 8 to 14 years (average, 11 years). Photographs of the erupted anterior teeth were taken in all twelve cases and plaster casts were made of both dental arches. It was thus possible to compare the teeth of different patients and not only the teeth of each patient with previous $x$-rays.

\section{Findings}

Upper Central Incisors.-The $42 x$ rays of unerupted upper central incisors were classified as follows: syphilitic or Hutchinsonian teeth (in a wider sense), thirteen; possibly syphilitic, nine; and normal, twenty.

In the twelve cases traced for follow-up, the upper central incisors of seven were in the syphilitic group and five were possibly syphilitic.

In the seven cases recorded as syphilitic on the basis of $x$ rays, the follow-up examination confirmed the earlier $x$-ray findings (Fig. 1A and Fig. 3A-D, opposite).

In the five possibly syphilitic cases, follow-up showed the teeth of one to be normal, and the teeth of two others were doubtfully syphilitic (Fig. 3F); one patient had one normal and one syphilitic upper central incisor (Fig. 3E), and the fifth patient showed enamel hypoplasia (Fig. 1B).

First Molars. $-X$ rays of unerupted first molars were taken in only ten cases. Three of them had $x$-ray signs in the upper centrals, but none in the first molars, not even the patient whose first molars proved to be of typical syphilitic bud form at the follow-up examination (Fig 4, opposite). Nor did the $x$ rays show enamel hypoplasia in the patient whose molars are seen in Fig. 1C.

\section{Discussion}

Since an $x$ ray is a shadow image of an object through which $x$ rays pass on to a film placed behind it, the shape and size of the image depend greatly on the angulation, i.e. on the relative positions of the $x$-ray source, the object, and the film in relation to each other. These spatial factors can seldom be optimally arranged when making an exposure of a living subject, and often one has to act quite "blindly". This is the case when an $x$-ray photograph is taken of an unerupted tooth. Its position may differ from the normal to an unexpected extent, and it may be turned on its longitudinal axis or be tilted in different directions. The image of a normal tooth on the film may then even appear pathological compared with the neighbouring teeth.

In $x$ rays of the anterior teeth the shape of the crown does not change very much with variations in the projection angle because the crown is fairly flat in the labiopalatinal direction. However, turning the tooth around its axis may lead to errors of interpretation; the projection of the lateral margin of the tooth usually becomes distorted (Fig. 3F). 

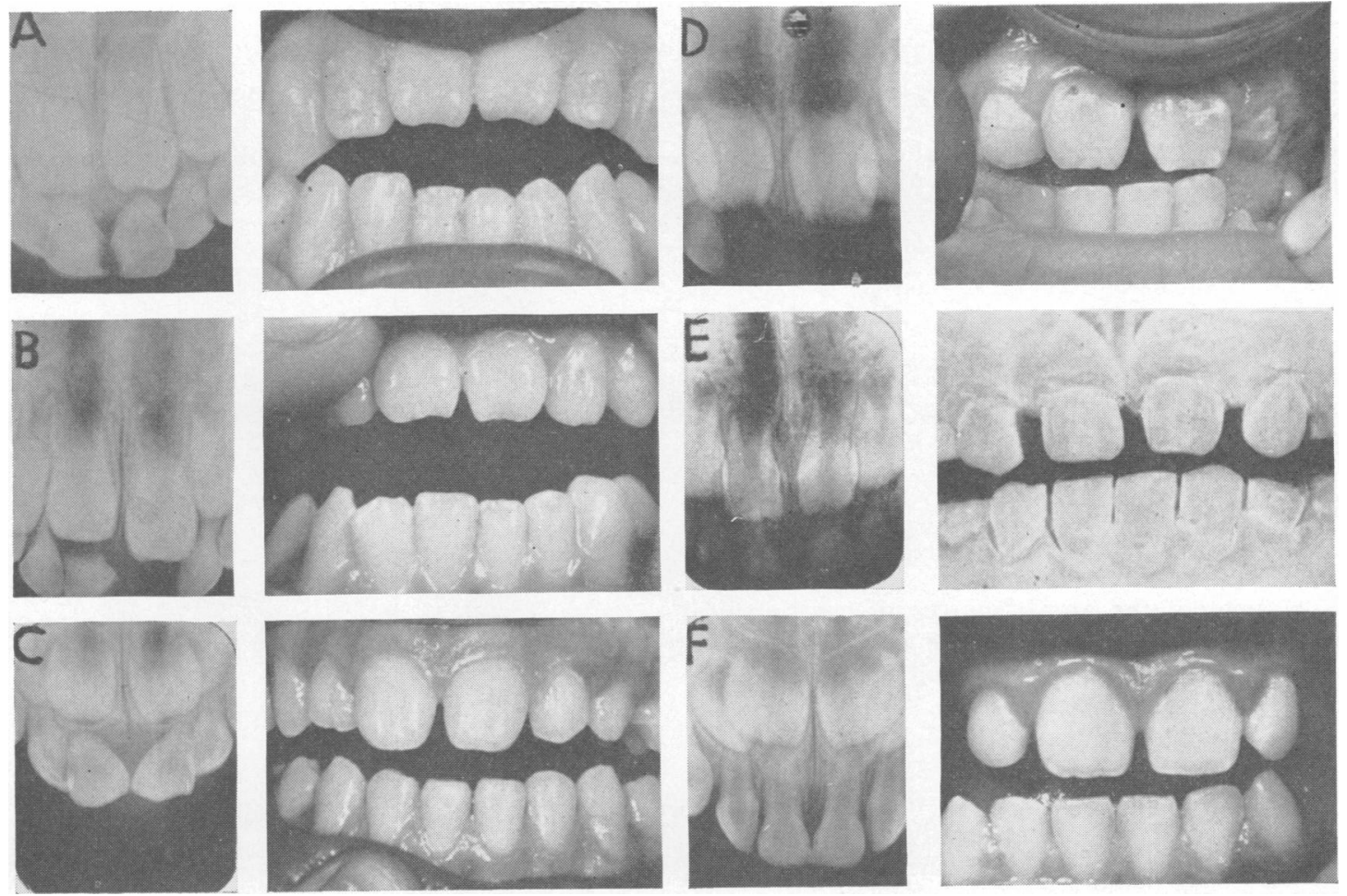

FIG. 3.-Unerupted permanent upper central incisors were interpreted as Hutchinsonian teeth in A-D, and as possibly syphilitic in $E$ and $F$ Follow-up examination showed that this interpretation had been correct in A-D and $F$, while in $E$ the left upper central incisor proved to be Hutchinsonian and the right was fairly normal.

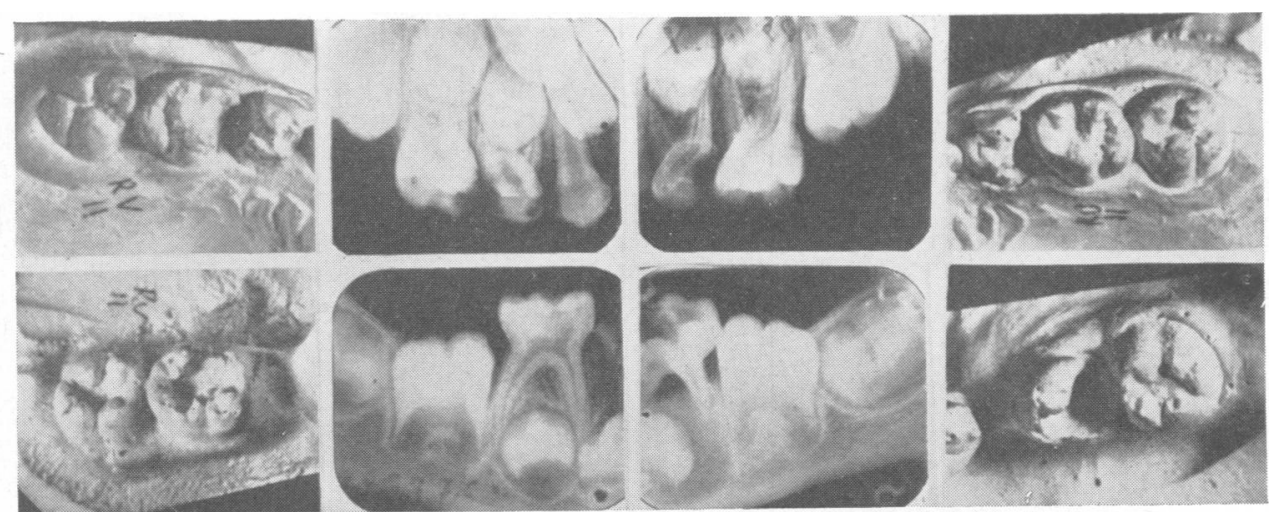

Fig. 4. $-X$ rays of unerupted first molars do not show a definite bud form. The follow-up examination reveals typical syphilitic bud molars. 
Fig. 5 illustrates a case in which, because of the error described, the tooth has the appc rance of ending in a sharp point. An error in the evaluation of the length of the tooth is yet more frequent, owing to variations in the vertical angle of projection, but this is less detrimental in the evaluation of morphological changes due to syphilis.

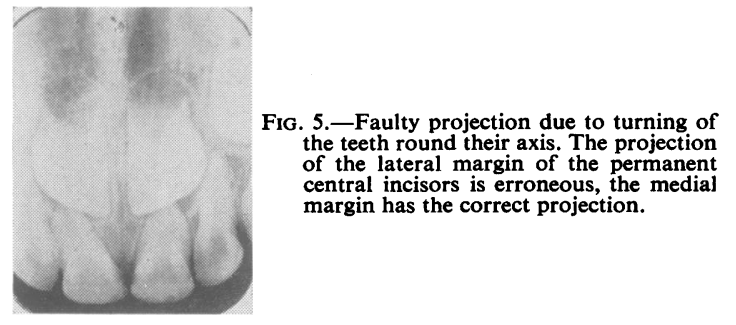

In spite of the above sources of error, typical syphilitic changes in the shape of the unerupted upper central incisors can generally be recognized in $x$ rays with reasonable accuracy.

The reported incidence of Hutchinsonian teeth in congenital syphilis varies from 30 to 50 per cent., depending upon the criteria for these teeth and for the diagnosis of congenital syphilis in each study. In the present study we required barrel-shaped incisors or convergence of their margins, but a crescentic notch in the cutting edge was not regarded as an absolute requirement. The criteria were the same for unerupted teeth in $x$ rays. Data as to the incidence of Hutchinsonian teeth observed by $x$ ray are scanty. Quinlan (1927) reported them in two patients out of fourteen, Sarnat and Shaw (1942) in four of sixteen, and Vilanova and Dulanto (1951) in one patient of four. These series added together give a total of seven out of 34 (about 20 per cent.). In our series of 42 patients the corresponding figure was higher (31 per cent.), which is nearer the figures reported for erupted incisors.

$X$-ray examination of unerupted molars proved unrewarding, chiefly because of technical difficulties. Fig. 6 shows an extracted upper first molar in four projections which can all be used in $x$-raying the teeth, and demonstrates how the same tooth appears to be of varying shape when seen from different angles. This is because the crown of a molar is of complex form. The shape of the lower first molar varies in the same way when observed by means of $x$ rays.

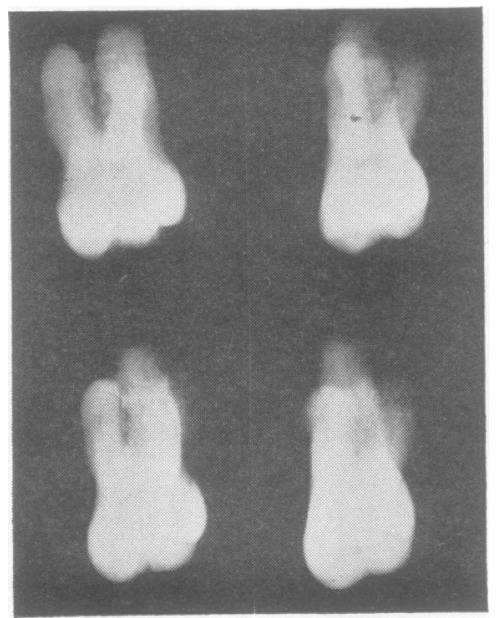

Fig. 6.- $X$ rays of an extracted upper first molar in the four projections which may occur when a patient is $x$-rayed.

It thus appears that the possible changes due to syphilis in unerupted first molars cannot be reliably demonstrated by $x$ rays, though gross enamel hypoplasia of the grinding surface may be seen. This opinion is not contradicted by the $x$-ray photographs of permanent first molars presented by Pincherle (1937), Sarnat, Schour, and Heupel (1941), or Sarnat and Shaw (1942), or by our own $x$-ray photographs of erupted molars of typical syphilitic bud form (Fig. 7).

In an attempt to reduce the technical sources of error we made experiments with a new $x$-ray apparatus, the orthopantomograph (Paatero, 1959), which enables all the teeth to be $x$ rayed in a single exposure

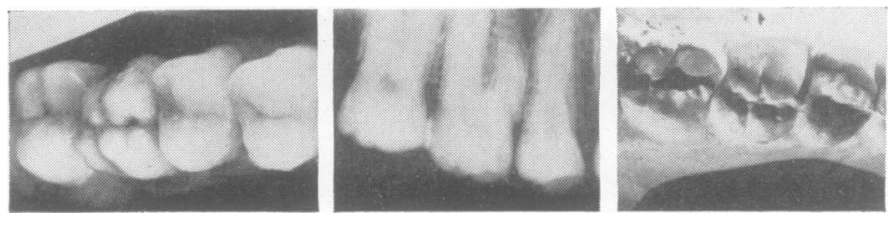

Fig. 7.-Photograph and $x$ ray of a bud form molar. The $x$ ray does not disclose this syphilitic shape of the molar. 


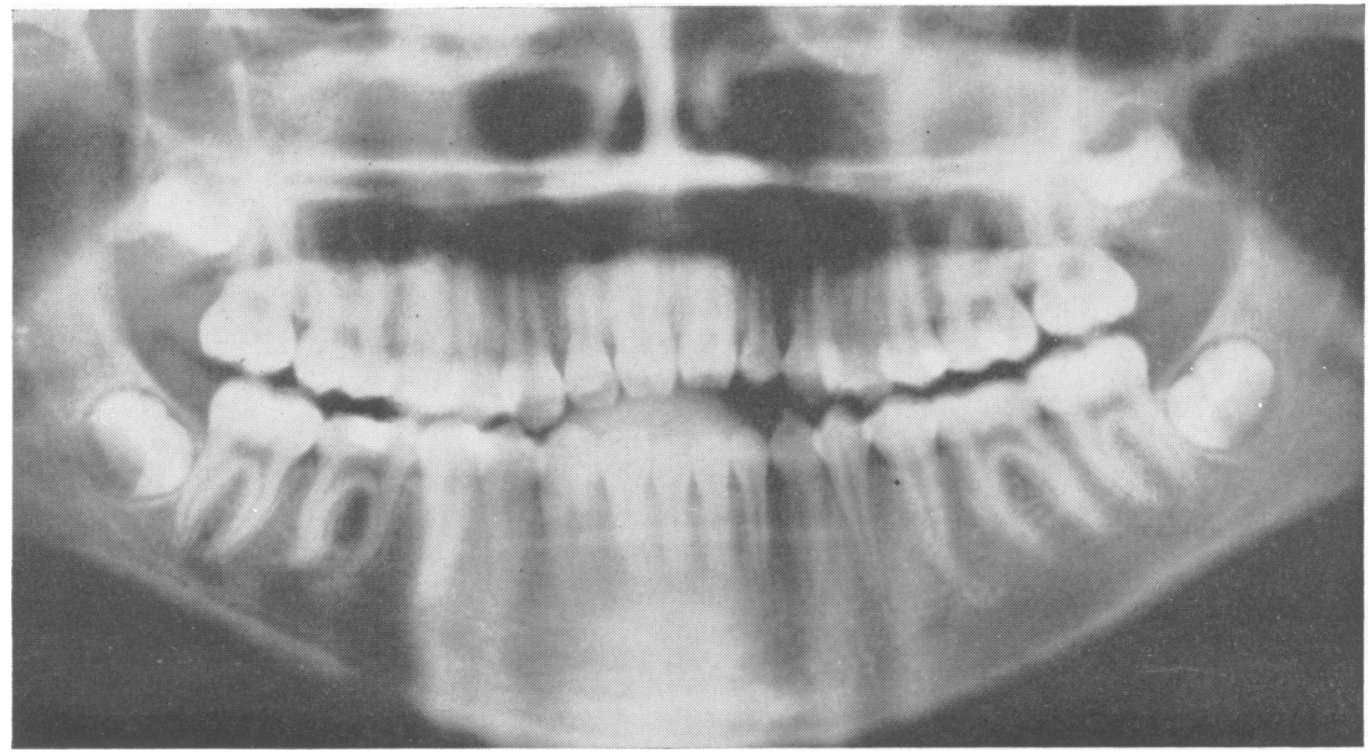

Fig. 8.-Orthopantomogram of the teeth of a patient with congenital syphilis.

on the same film; the projection is ideal (orthoradially), the exposure being made perpendicularly to the longitudinal axis of the tooth (Fig. 8). The changes in the upper central incisors were visible in these films, but not even in them was the bud form of molars clearly recognizable. The apparatus has the advantage that $x$ rays of different patients are comparable since the vertical angulation can be kept practically unchanged from case to case. Fig. 8 shows a panorama, an orthopantomogram, obtained by this means. The accuracy of the images might be further increased by using slower, finer-grain films and screens, as well as a focus smaller than the $2 \mathrm{~mm}$. used at present.

\section{Summary}

The $x$-ray appearances of unerupted permanent teeth in 42 patients with congenital syphilis are presented, with follow-up studies of twelve of these patients after the eruption of the teeth.

The unerupted upper central incisors of thirteen patients (31 per cent.) were interpreted as Hutchinsonian teeth, and at a follow-up examination of seven of these cases, the erupted teeth confirmed the previous $x$-ray findings. In a further nine patients the $x$ rays showed possible syphilitic changes; five were traced for the follow-up study and Hutchinsonian teeth were found in only one of them. It thus appears that congenital syphilitic changes in the shape of unerupted upper central incisors can be reliably demonstrated by $x$ rays.

The errors that may arise from variations in the angle of projection are discussed. These sources of error, together with the complex shape of the molar crown, prevent the use of $x$ rays for the diagnosis of syphilitic bud molars. To reduce errors in projection experiments have been made with the orthopantomograph, a new $x$-ray apparatus with which an orthoradial panorama of all the teeth is obtained in a single exposure.

\section{REFERENCES}

Meyer-Buley, H. (1930). Derm. Z., 58, 313.

Moon, H. (1877). Trans. odont. Soc. (Lond.), n.s. 9, 223. (1884). In T. Bryant "A Manual for the Practice of Surgery", 4th ed.; vol. 1, p. 637. Churchill, London.

Paatero, Yrjö V. (1959). Suom. hammaslääk. toim. (Helsinki), 55, 172.

Pflüger, H. (1924). Münch. med. Wschr., 71, 605.

Pincherle, B. (1937). Minerva Med. (Torino), Sez. sci., 28 (2), 8 .

Pitts, A. T. (1927). Proc. roy. Soc. Med., 20, 1531.

Quinlan, R. V. (1927). Arch. Derm. Syph. (Chicago), 16, 605.

Sarnat, B. G., Schour, I., and Heupel, R. (1941). J. Amer. med. Ass., 116, 2745.

and Shaw, N. G.(1942). Amer. J. Dis. Child., 64, 771.

Stokes, J. H., and Gardner, B. S. (1923). J. Amer. med. Ass., 80, 28.

Vilanova, X., and Dulanto, F. De (1951). Act. dermosifilogr. (Madr.), 42, 682. 
Radiographie des dents permanentes non percées dans la syphilis congénitale

\section{Résumé}

Les auteurs présentent les radiographies des dents permanentes non percées de 42 syphilitiques congénitaux, et en suivent 12 après l'éruption des dents. Ils estimèrent que les incisives centrales supérieures de 13 malades ( $31 \%$ ) étaient du type d'Hutchinson, ce qui fut corroboré dans 7 de ces cas par l'examen ultérieur des dents percées. Chez 9 autres malades, les radiographies indiquaient la possibilité de lésions syphilitiques; 5 furent suivis et un seul avait des dents d'Hutchinson.
Il semble donc que les lésions syphilitiques congénitales comme les incisives centrales supérieures non percées puissent être démontrées avec certitude par les rayons X.

Les auteurs discutent les erreurs que peuvent causer les variations de l'angle de projection. Ces sources d'erreur, et la forme complexe de la couronne molaire, excluent l'emploi des rayons $\mathrm{X}$ pour le diagnostic des molaires syphilitiques non percées. Pour réduire les erreurs de projection, les auteurs ont fait des essais avec l'orthopantomographe, un nouvel appareil de radiographie permettant d'obtenir un panorama orthoradial de toutes les dents en une seule pose. 